\title{
Clinical Application of Scalp Markers and Three-Dimensional Sliced Computed Tomography Reconstructions of the Skull Transverse-Sigmoid Sinus Groove in the Retrosigmoid Approach
}

\author{
Chao WANG ${ }^{1}$, Guoqiang HAN ${ }^{1}$, Chao YOU ${ }^{2}$, Chuangxi LIU ${ }^{1}$ \\ ${ }^{1}$ GuiZhou Provincial People's Hospital, Department of Neurosurgery, GuiYang, China \\ ${ }^{2}$ West China Hospital of Sichuan University, Department of Neurosurgery, Chengdu, China
}

\section{ABSTRACT}

AIM: To explore the clinical value of bone flap creation and the sinus protection in the approach of retrosigmoid keyhole craniotomy with the guidance of three-dimensional (3D) sliced computed tomography (CT) reconstruction of the skull transverse sinus and sigmoid sinus groove.

MATERIAL and METHODS: The scalp tracings of the transverse sinus and sigmoid sinus groove of 108 posterior fossa lesion patients were delineated by gentian violet, which relies on the relationship between its 3D reconstruction location and scalp marker. The craniotomy was executed with the guidance of its surface tracings. The intraoperative findings of exposure and damage of transverse sinus, sigmoid sinus, morphology, stability, complications, and postoperative appearance of bone flap restoration were evaluated.

RESULTS: Morphological analysis of the transverse-sigmoid sinus groove showed right superiority, left superiority, and balanced type in 61, 18, and 29 cases, respectively and the relationship between the asterion and the transverse-sigmoid sinus groove showed that asterion sites were located in the upper portion, onto, and below the transverse and sigmoid sinus groove in 19, 68, and 21 cases, respectively. Good intraoperative exposure without damage of transverse sinus and sigmoid sinus, good stability and appearance of bone flap restoration, and no postoperative pseudomeningocele were obtained after using this method to locate the transverse sinus and sigmoid sinus.

CONCLUSION: The 3D sliced CT reconstruction of the skull transverse sinus and sigmoid sinus groove was helpful in the approach of retrosigmoid craniotomy for sinus exposure, sinus protection, and the prevention of cerebrospinal fluid leakage and pseudomeningocele.

KEYWORDS: Retrosigmoid approach, Sigmoid sinus, Transverse sinus, Three-dimensional sliced computed tomography reconstruction

\section{INTRODUCTION}

$\mathrm{T}$ The retrosigmoid approach is a common surgical method used for the cerebellopontine angle (CPA) lesions $(5,24,26)$, petroclival meningiomas $(7)$, inferior lesions of the tentorium (11), and trigeminal microvascular decompression (12). We retrospectively reported on 108 posterior fossa lesion patients who had preoperative localization of the skull transverse-sigmoid sinus groove and underwent retrosigmoid keyhole surgery in our institution. 


\section{MATERIAL and METHODS}

\section{Patients}

A total of 108 posterior fossa lesion patients, who had preoperative localization of the skull transverse-sigmoid sinus groove and underwent retrosigmoid surgery in our Neurosurgery Department between January 2010 and January 2015, were enrolled in our study. All diagnoses were confirmed by clinical manifestations, neuroimaging, and histopathological examination. The patients consisted of 65 males and 43 females and were aged between 23 and 68 years old (with a mean age of 41.7 years) at the time of surgery. Preoperative and postoperative sliced computed tomography (CT) scan, magnetic resonance imaging (MRI), and complications were analyzed retrospectively. Clinical manifestations of headache, tinnitus, hearing loss, ataxia, and trigeminal neuralgia were observed in 25, 9, 23, 16, and 35 cases, respectively.

Preoperative MRI of 73 patients showed lesions located in the CPA, petroclival area, and inferior lesions of the tentorium of 39,27 , and 7 patients, respectively. The lesion diameters were between $2.0 \mathrm{~cm}$ and $4.5 \mathrm{~cm}$. The responsible vascular system in 35 patients with trigeminal neuralgia was found using threedimensional time-of-flight magnetic resonance angiography. Retrosigmoid keyhole approach is the best surgical approach in the preoperative appraisal.

\section{Surgical Modifications}

Retrosigmoid keyhole approach was applied. Two medical grinding wheels with diameters of $1.5 \mathrm{~cm}$ were obliquely placed as a scalp marker on the angular area that consisted of the superior nuchal line and the posterior margin of the mastoid, and the two external fiducials should be in parallel with the posterior margin of the mastoid. Sliced CT scanning $(0.75 \mathrm{~mm})$ of the skull was then performed. 3D sliced CT reconstructions of the transverse-sigmoid sinus groove were performed using an imaging workstation. The morphological characteristics of width, length, and trace of the transversesigmoid sinus groove were obtained in an inner observation after the reconstruction had down. The relationships between the transverse sinus, sigmoid sinus, mastoid air cell, and the medical grinding wheel were determined from the transverse and coronal reconstructions, whereas the overall view of the transverse sinus, sigmoid sinus, and scalp marker were obtained using the fluoroscopy imaging software. The scalp tracings of the transverse-sigmoid sinus groove were delineated by using gentian violet according to the relationship between its $3 \mathrm{D}$ reconstruction location and the scalp marker. Skin incision and craniotomy were performed by following the surface tracings. All surgical procedures were performed after induction of general anesthesia and electrophysiological monitoring. The patient was placed in a lateral posture position, with the head fixed in a Mayfield head holder. Oblique skin incision was started $0.5 \mathrm{~cm}$ above the upper margin of the transverse sinus groove and $1 \mathrm{~cm}$ behind the posterior margin of the transverse sinus groove. The scalp was incised layer by layer, and the skull was exposed using a mastoid retractor. A bone flap with a diameter of 2.0-3.0 $\mathrm{cm}$ and with exposed inferior margin of the transverse sinus and posterior margin of the sigmoid sinus was removed using high-speed drilling and then preserved. The opened mastoid air cell was tightly blocked with bone wax. The dura was opened, and the transverse-sigmoid sinus junction was fully exposed under a microscope. The dura was water-tight sutured and suspended onto the bone flap after the operation with or without the assistance of an endoscope. The scalp was layer-sutured (Figures 1A-E, 2A-L).

\section{RESULTS}

\section{Histopathological Examination}

Acoustic neuroma, cholesteatoma, arachnoid cyst, and meningioma were observed in $30,4,6$, and 33 patients, respectively.

\section{Preoperative Three-dimensional Computed Tomography Findings}

Morphological analysis of the transverse-sigmoid sinus groove showed right superiority, left superiority, and balanced type in 61, 18, and 29 cases, respectively. Moreover, the morphological characteristics were highly in accordance with enhanced MRI of the transverse-sigmoid sinus. Analysis of the relationships between the transverse-sigmoid sinus joint and the mastoid air cell showed that 17 cases had the mastoid air cell extended to the exterior bone of the transverse-sigmoid sinus joint (Figures $3 \mathrm{~A}-\mathrm{I}, 4 \mathrm{~A}-\mathrm{C}$ ). Analysis of the relationship between the asterion and the transverse-sigmoid sinus groove showed that asterion sites were located in the upper portion, onto, and below the transverse and sigmoid sinus groove in 19,68 , and 21 cases, respectively (Figure 5A-C).

\section{Intraoperation Findings}

The bone flap diameter was between $2 \mathrm{~cm}$ and $3 \mathrm{~cm}$, and sufficient intraoperative exposure without damage to the transverse and sigmoid sinuses was achieved. The excision extent was confirmed by intraoperative inspection, and 68 of 73 cases had total lesion excision. Endoscopy was performed in 34 cases to locate the bleeding site and re-confirm the excision extent (Figure 6A-C). Five cases had subtotal excision in which the residue was tightly adhered to the brainstem or located in the internal auditory canal. This condition was re-confirmed by intraoperative endoscopy. High stability and acceptable appearance of the restored bone flap were observed in all cases.

\section{Manifestations and Signs}

Follow-up studies from 18 months to 6 years showed that headache was cured in 21 of the 25 cases (84\%) and was significantly improved in 4 cases (16\%); tinnitus was cured in 7 of the 9 cases $(77.78 \%)$ and was significantly improved in 2 cases (22.22\%); hearing loss was improved in 4 of the 23 cases (17.39\%), deteriorated in 17 cases $(73.91 \%)$, and showed no variation in 2 cases $(8.70 \%)$; ataxia was cured in 13 of the 16 cases $(81.25 \%)$ and significantly improved in 3 cases (18.75\%). Moreover, facioplegia was observed in 6 patients, of which 2, 2, 1, and 1 exhibited grade II, grade III, 

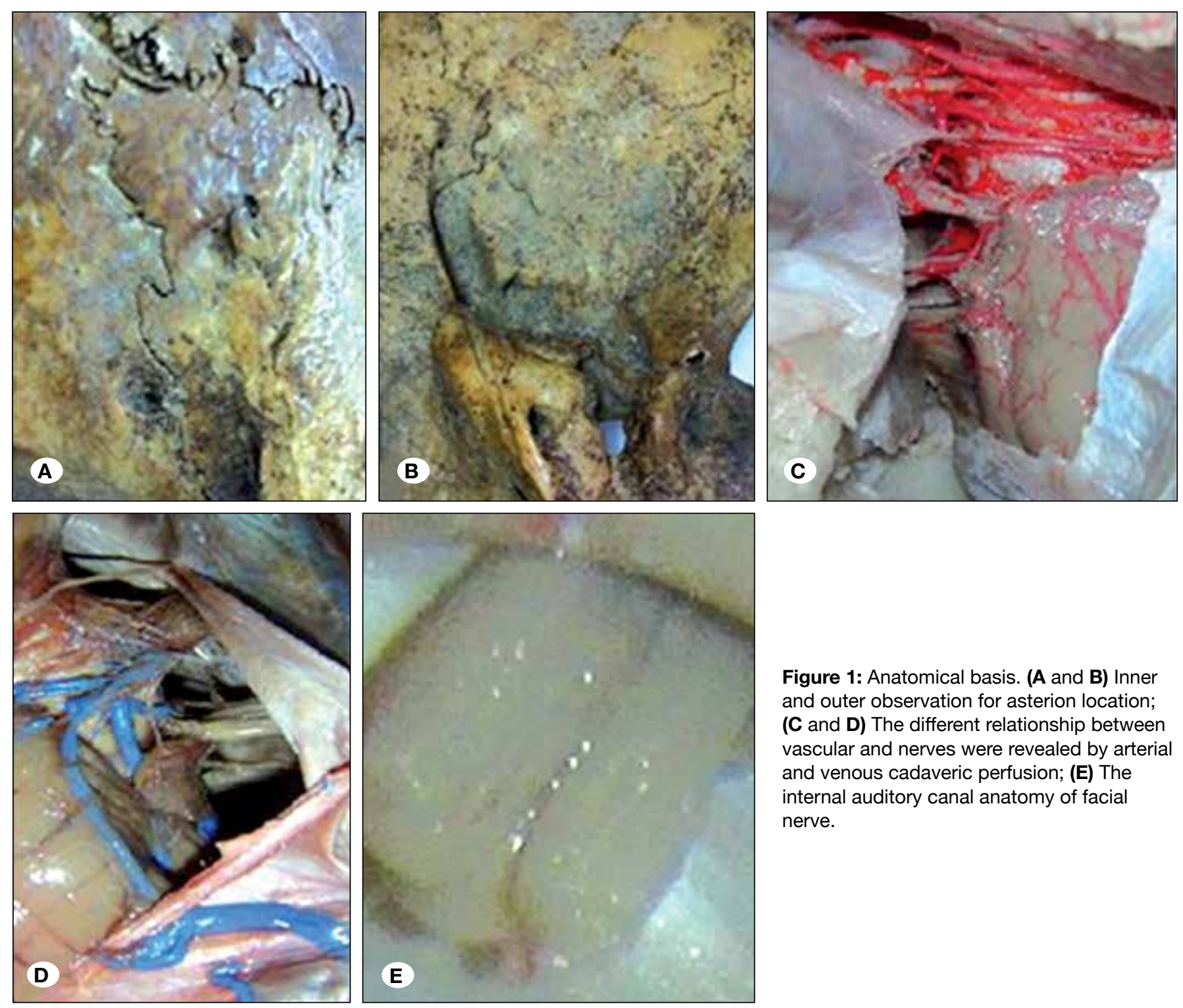

Figure 1: Anatomical basis. (A and B) Inner and outer observation for asterion location; (C and $\mathbf{D})$ The different relationship between vascular and nerves were revealed by arterial and venous cadaveric perfusion; (E) The internal auditory canal anatomy of facial nerve.

grade IV, and grade V, respectively, according to the HouseBrackmann scale.

\section{Complications}

No postoperative pseudomeningocele, cerebrospinal fluid (CSF) otorrhea, and operative mortality were recorded in our series.

\section{Follow-up CT and MRI scans}

During the follow-up, high stability and good appearance of the restored bone flap, no postoperative pseudomeningocele, and mastoid effusion were found using postoperative CT reconstruction. MRI scans indicated that the preoperative lesion disappeared in 68 cases and was significantly reduced in 5 cases. No postoperative pseudomeningocele and mastoid effusion were found.

\section{DISCUSSION}

The retrosigmoid approach is a common surgical technique for CPA lesion, petroclival meningiomas, inferior lesions of the tentorium, and trigeminal microvascular decompression. With the aid of endoscopy, we can fully understand the neurovascular structures and resection degree of lesions in the CPA or internal auditory canal. Retrosigmoid keyhole approaches are increasingly being used to replace large or removed bone flaps $(1,2,14,15,17,19,20,31)$.

In the retrosigmoid keyhole approach, the transversesigmoid sinus junction should be fully exposed $(3,23)$. In the past, neurosurgeons generally depend on the asterion and related sutures to determine the position of the transversesigmoid sinus junction $(25,27,29)$. However, the transversesigmoid sinuses and junction sites of different people exhibit different anatomical characteristics $(13,18,21,28,30)$, 

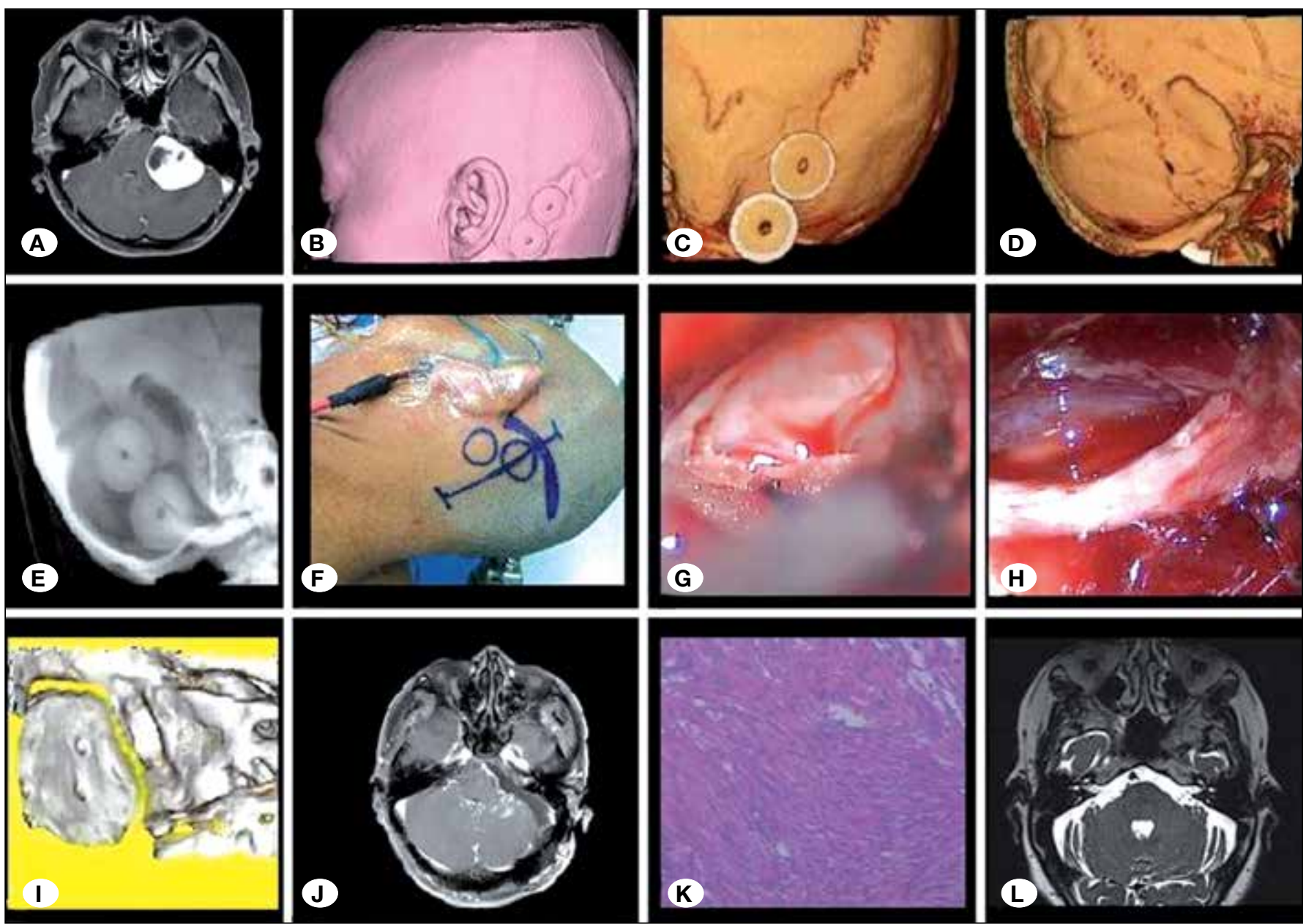

Figure 2: (A) Preoperational magnetic resonance imaging. (B and C) Two medical grinding wheels with diameters of $1.5 \mathrm{~cm}$ as a scalp marker. (D) The inner observation of asterion. (E) The relationship between transverse sinus, sigmoid sinus groove, and scalp marker was obtained by the inner program of fluoroscopy imaging. (F) The scalp tracings of the transverse sinus and sigmoid sinus groove according to scalp marker. (G and $\mathbf{H})$ The facial nerve protection. (I) Postoperative three-dimensional computed tomography reconstruction. (J) Postoperative magnetic resonance imaging. (K) Pathological examination of acoustic neuroma. (L) Follow-up magnetic resonance imaging.

and in some cases, retrosigmoid craniotomy standardized according to anatomic landmarks raises the risk for sinus injury because of the variations in their location (8). Obtaining accurate preoperative data on the location of the transversesigmoid sinus and junction is more important than related or experienced things (4). In our method, we were able to use the imaging workstation fully to obtain the width, length, and trace characteristics of the transverse-sigmoid sinus based on inner observation of 3D sliced CT reconstruction. The specific and general relationships between the transverse sinus, sigmoid sinus, and scalp marker (grinding wheels) were accurately expressed in the coronal reconstruction and inner template of fluoroscopy imaging. The scalp tracings of the transverse-sigmoid sinus groove were accurately delineated by gentian violet according to the relationship between its 3D reconstruction location and the scalp marker. The sufficient intraoperative exposure achieved in this study, without causing damage to the transverse sinus and sigmoid sinus, as well as the high stability and good appearance of the restored bone flap, validate the usefulness and reliability of the proposed method.

The most common complication in the retrosigmoid approach is CSF leakage (5), which is partly caused by the incomplete sealing of the opened mastoid air cell (10). Preoperative knowledge of the development of mastoid air cells and intraoperative complete sealing of the opened mastoid air cell would help reduce the incidence of CSF leakage (22). Another complication is pseudomeningocele, in which excessive intraoperative bone loss increases the incidence rate of pseudomeningocele $(6,9,16)$. Preoperative localization of the skull transverse-sigmoid sinus groove contributes to obtaining sufficient intraoperative exposure without damaging the transverse sinus and sigmoid sinus and also effectively prevents bone loss. These factors reduce the incidence of pseudomeningocele. 

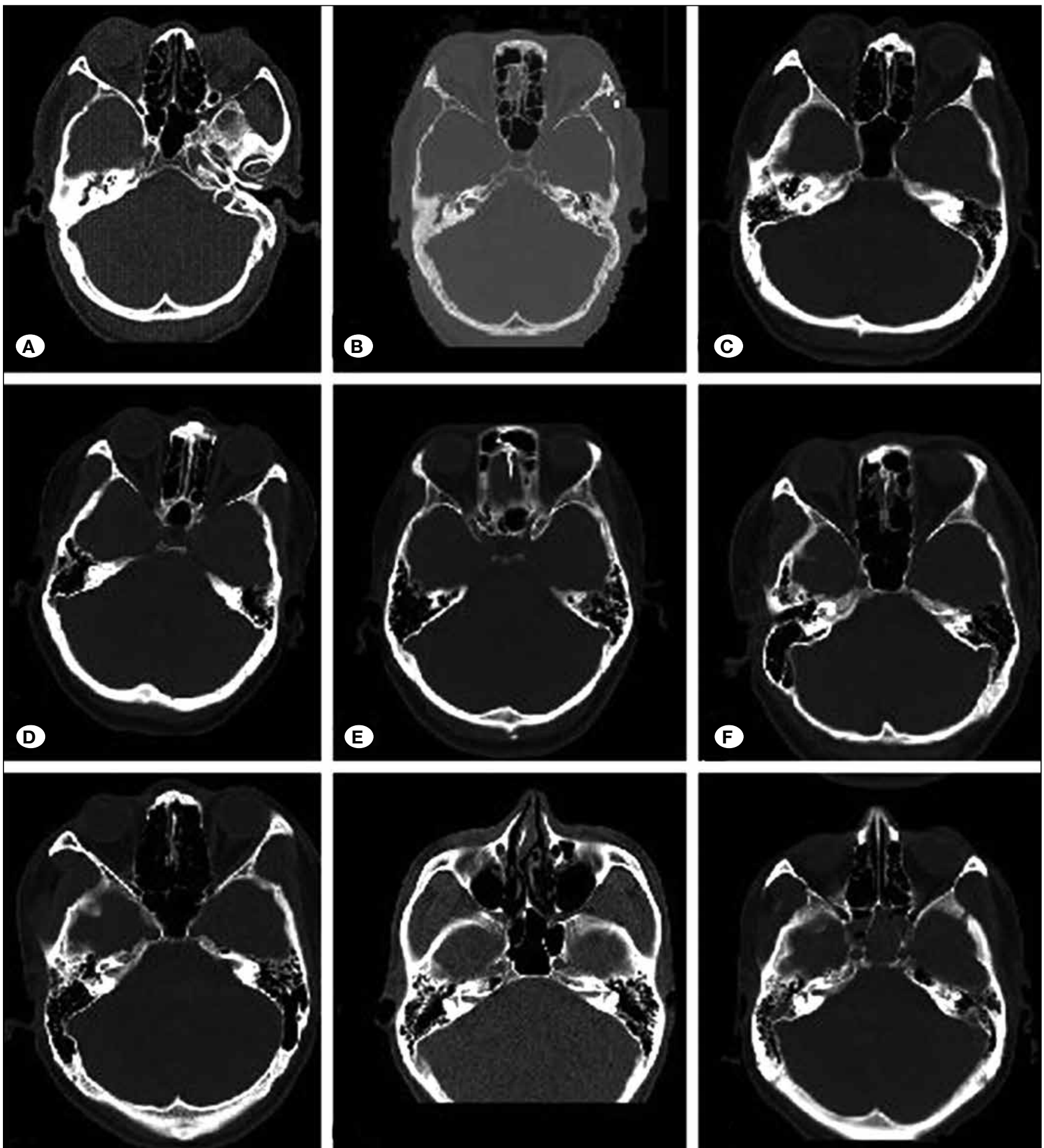

G

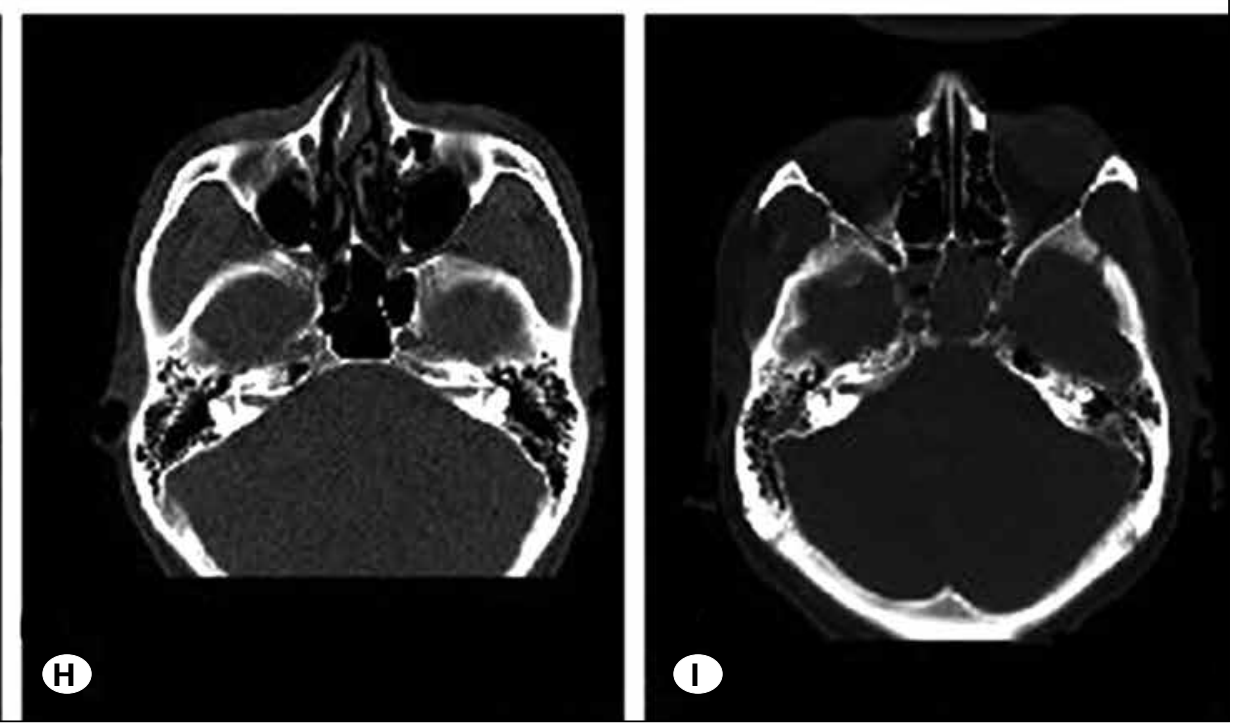

Figure 3: Different types of transverse, sigmoid sinus groove, and the mastoid air cell were found in our series. 

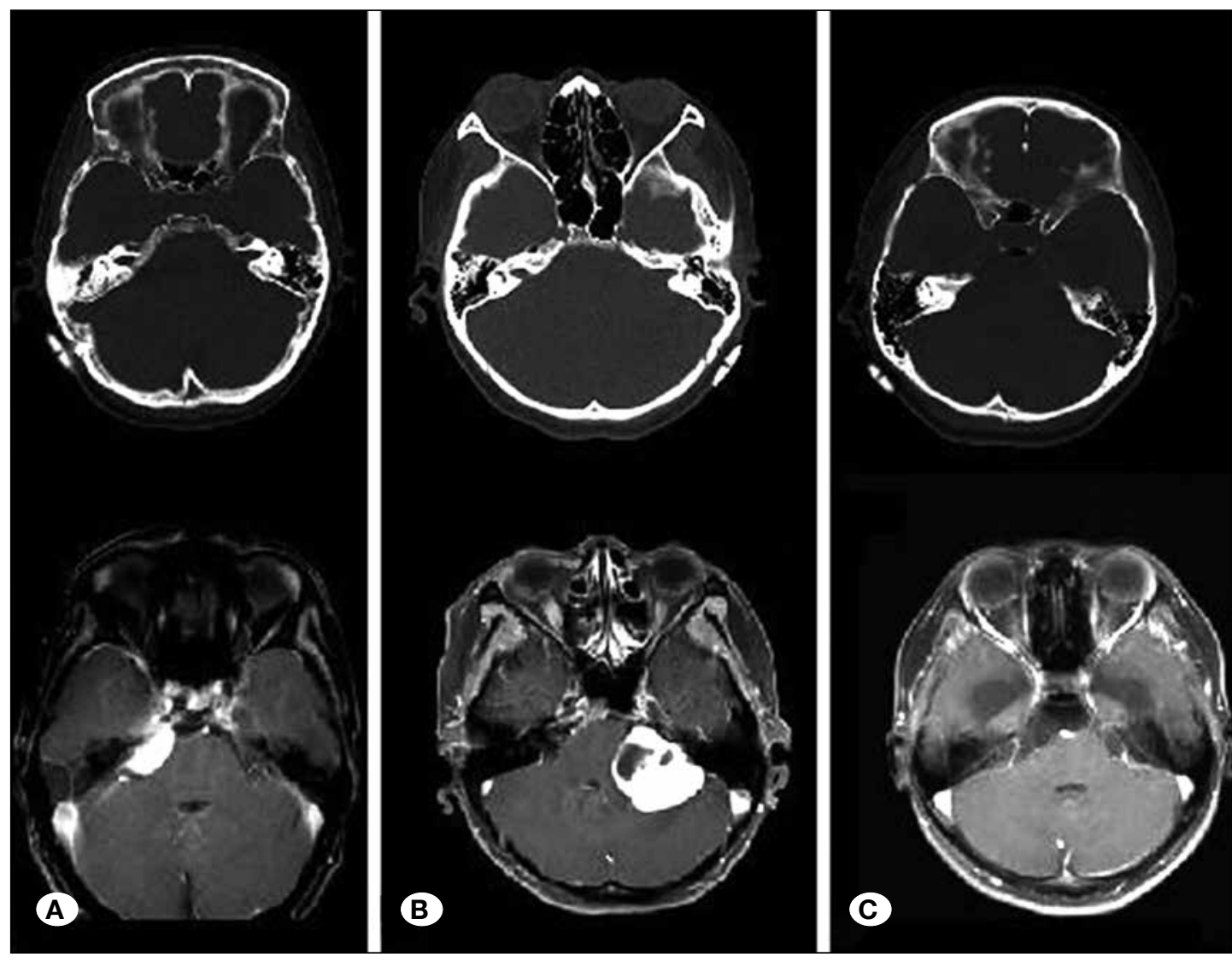

Figure 4:

Morphological

characteristic of

transverse-sigmoid

sinus groove in

computed tomography,

magnetic resonance

imaging showed

right superiority,

left superiority, and balanced type.
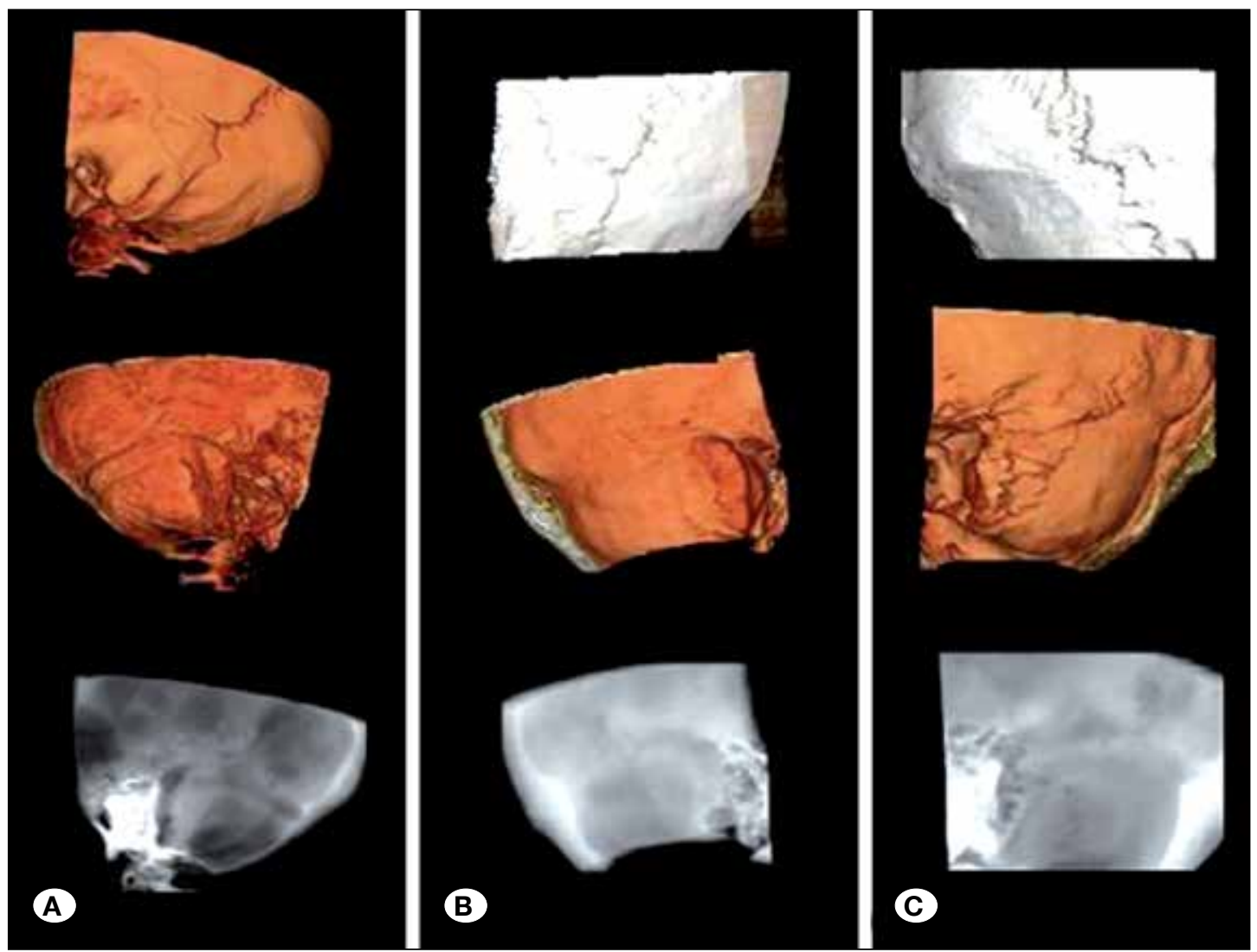

Figure 5: The

relationship between asterion and the transverse, sigmoid sinus groove. (A) The asterion site located (A) above, (B) onto, and (C) below the transverse and sigmoid sinus groove. 

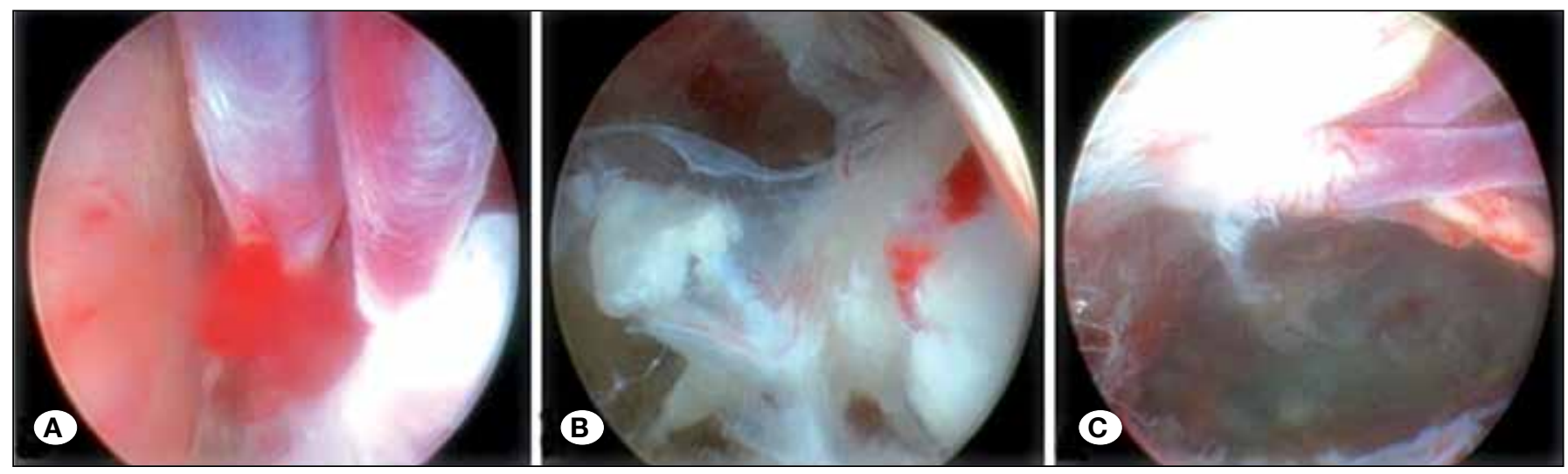

Figure 6: The intraoperative finding after endoscope was performed. (A) The bleeding site was confirmed when microscopy was in vain, (B) the lesion residue was found after the microscopic total lesion excision, and (C) the total lesion excision was re-confirmed by intraoperative assistance of endoscope.

\section{CONCLUSION}

The clinical application of scalp markers and 3D sliced CT reconstructions of the skull transverse-sigmoid sinus groove are useful in locating and protecting the transverse and sigmoid sinuses and reducing the postoperative complications of the retrosigmoid keyhole approach. With the aid of the endoscopy, we can fully understand the neurovascular structures and resection degree of lesions in the CPA or internal auditory canal.

\section{REFERENCES}

1. Chen L, Chen LH, Ling F, Liu YS, Samii M, Samii A: Removal of vestibular schwannoma and facial nerve preservation using small suboccipital retrosigmoid craniotomy. Chin Med J (Engl) 123: 274-280, 2010

2. Chen LH, Liu YS, Yuan XR, Fang JS, Ma JR, Xi J, Yang ZQ, Huo L: Keyhole microsurgery for acoustic neurinomas through suboccipital retrosigmoid sinus approach. Ai Zheng 21: 11361140, 2002

3. Da Silva EB Jr, Leal AG, Milano JB, da Silva LF Jr, Clemente RS, Ramina R: Image-guided surgical planning using anatomical landmarks in the retrosigmoid approach. Acta Neurochir (Wien) 152: 905-910, 2010

4. Day JD, Tschabitscher M: Anatomic position of the asterion. Neurosurgery 42: 198-199, 1998

5. Erdogan E, Civelek E, Onal MB, Solmaz I, Kural C, Yakupoglu $\mathrm{H}$ : A new method of patient's head positioning in suboccipital retrosigmoid approach. Neurol India 57: 777-779, 2009

6. Ferreira M, Walcott BP, Nahed BV, Sekhar LN: Vertebral artery pexy for microvascular decompression of the facial nerve in the treatment of hemifacial spasm. J Neurosurg 114:18001804, 2011

7. Ghanta RK, Mohammad A: Large ventral foramen magnum meningioma: Retrosigmoid suboccipital approach. J Craniovertebr Junction Spine 2:103-104, 2011
8. Hamasaki T, Morioka M, Nakamura H, Yano S, Hirai T, Kuratsu $\mathrm{J}$ : A 3-dimensional computed tomographic procedure for planning retrosigmoid craniotomy. Neurosurgery 64(5 Suppl 2): 241-245, 2009

9. Harter DH, Swanger R, Tenner M: Growing burr hole: Enlarging pseudomeningocele at the site of a craniostomy. Childs Nerv Syst 20: 127-130, 2004

10. Hong KS, Park K: Delayed progressive extradural pneumatocele due to incomplete sealing of opened mastoid air cell after micro-vascular decompression. J Korean Neurosurg Soc 47: 477-479, 2010

11. Javalkar V, Banerjee AD, Nanda A: Posterior cranial fossa meningiomas. J Neurol Surg B Skull Base 73: 1-10, 2012

12. Kabatas S, Albayrak SB, Cansever T, Hepgul KT: Microvascular decompression as a surgical management for trigeminal neuralgia: A critical review of the literature. Neurol India 57: 134-138, 2009

13. Koesling S, Kunkel P, Schul T: Vascular anomalies, sutures and small canals of the temporal bone on axial CT. Eur J Radiol 54: 335-343, 2005

14. Komatsu F, Komatsu M, Di leva A, Tschabitscher M: Endoscopic approaches to the trigeminal nerve and clinical consideration for trigeminal schwannomas: A cadaveric study. J Neurosurg 117: 690-696, 2012

15. Kumon Y, Kohno S, Ohue S, Watanabe H, Inoue A, Iwata S, Ohnishi T: Usefulness of endoscope-assisted microsurgery for removal of vestibular schwannomas. J Neurol Surg B Skull Base 73: 42-47, 2012

16. Legnani FG, Saladino A, Casali C, Vetrano IG, Varisco M, Mattei L, Prada F, Perin A, Mangraviti A, Solero CL, DiMeco F: Craniotomy vs. craniectomy for posterior fossa tumors: A prospective study to evaluate complications after surgery. Acta Neurochir (Wien) 155: 2281-2286, 2013

17. Li Z, Lan Q: Retrosigmoid keyhole approach to the posterior cranial fossa: An anatomical and clinical study. Eur Surg Res 44: 56-63, 2010

18. Ma Z, Li M, Cao Y, Chen X: Keyhole microsurgery for trigeminal neuralgia, hemifacial spasm and glossopharyngeal neuralgia. Eur Arch Otorhinolaryngol 267:449-454, 2010 
19. Mattox DE, Hudgins $P$ : Algorithm for evaluation of pulsatile tinnitus. Acta Otolaryngol 128:427-431, 2008

20. Mostafa BE, El Sharnoubi M, Youssef AM: The keyhole retrosigmoid approach to the cerebello-pontine angle: Indications, technical modifications, and results. Skull Base 18: 371-376, 2008

21. Mwachaka PM, Hassanali J, Odula PO: Anatomic position of the asterion in Kenyans for posterolateral surgical approaches to cranial cavity. Clin Anat 23: 30-33, 2010

22. Park JS, Kong DS, Lee JA, Park K: Intraoperative management to prevent cerebrospinal fluid leakage after microvascular decompression: Dural closure with a "plugging muscle" method. Neurosurg Rev 30: 139-142, 2007

23. Quiñones-Hinojosa A, Chang EF, Lawton MT: The extended retrosigmoid approach: An alternative to radical cranial base approaches for posterior fossa lesions. Neurosurgery 58(4 Suppl 2): ONS 208-214, 2006

24. Samii M, Gerganov V, Samii A: Improved preservation of hearing and facial nerve function in vestibular schwannoma surgery via the retrosigmoid approach in a series of 200 patients. J Neurosurg 105: 527-535, 2006

25. Sheng B, Lv F, Xiao Z, Ouyang Y, Lv F, Deng J, You Y, Liu N: Anatomical relationship between cranial surface landmarks and venous sinus in posterior cranial fossa using CT angiography. Surg Radiol Anat 34: 701-708, 2012
26. Silva J, Cerejo A, Duarte F, Silveira F, Vaz R: Surgical removal of giant acoustic neuromas. World Neurosurg 77: 731-735, 2012

27. Tubbs RS, Loukas M, Shoja MM, Bellew MP, Cohen-Gadol AA: Surface landmarks for the junction between the transverse and sigmoid sinuses: Application of the "strategic" burr hole for suboccipital craniotomy. Neurosurgery 65 Suppl 6: 37-41, 2009

28. Uz A, Ugur HC, Tekdemir I: Is the asterion a reliable landmark for the lateral approach to posterior fossa? J Clin Neurosci 8: 146-147, 2001

29. Xia L, Zhang M, Qu Y, Ren M, Wang H, Zhang H, Yu C, Zhu $\mathrm{M}$, Li J: Localization of transverse-sigmoid sinus junction using preoperative 3D computed tomography: Application in retrosigmoid craniotomy. Neurosurg Rev 35: 593-598, 2012

30. Xue J, Li T, Sun X, Liu Y: Focal defect of mastoid bone shell in the region of the transverse-sigmoid junction: A new cause of pulsatile tinnitus. J Laryngol Otol 126: 409-413, 2012

31. Zhu W, Mao Y, Zhou LF, Zhang R, Chen L: Keyhole approach surgery for petroclival meningioma. Chin Med J (Engl) 119: 1339-1342, 2006 